\title{
CFD Analysis of Heat Transfer and Friction Factor Characteristics in a Circular Tube Fitted with Quadrant-Cut Twisted Tape Inserts
}

\author{
Sami D. Salman, ${ }^{1,2}$ Abdul Amir H. Kadhum, ${ }^{1}$ Mohd S. Takriff, ${ }^{1}$ and Abu Bakar Mohamad \\ ${ }^{1}$ Department of Chemical and Process Engineering, Faculty of Engineering and Built Environment, Universiti Kebangsaan Malaysia, \\ 43600 Bangi, Selangor, Malaysia \\ ${ }^{2}$ Biochemical Engineering Department, Al-Khwarizmi College of Engineering, University of Baghdad, Baghdad 47024, Iraq
}

Correspondence should be addressed to Sami D. Salman; sami.albayati@gmail.com

Received 20 June 2013; Revised 7 September 2013; Accepted 9 September 2013

Academic Editor: Anuar Ishak

Copyright (C) 2013 Sami D. Salman et al. This is an open access article distributed under the Creative Commons Attribution License, which permits unrestricted use, distribution, and reproduction in any medium, provided the original work is properly cited.

\begin{abstract}
This paper reports numerical investigations of heat transfer and friction factor characteristics in swirling flow conditions using CFD simulation. A commercial CFD package, FLUENT 6.3.26, was used in this study. 3D models for circular tube fitted with classical and quadrant-cut twisted tape (QCT) inserts with three twist ratios $(y=2.93,3.91$, and 4.89) and different cut depths $(w=0.5$, 1.0 , and $1.5 \mathrm{~cm}$ ) were generated for the simulation. The data obtained from the CFD simulation were verified with the literature correlations of plain tube with the discrepancy of less than $\pm 8 \%$ for Nusselt number and $\pm 10 \%$ for friction factor. The results show that there was a significant increase in heat transfer coefficient and friction factor in the tube fitted with quadrant-cut twisted tape (QCT) with decreasing of twist ratio $(y)$ and cut depth $(w)$. Furthermore, the configuration of QCT insert with a twist ratio of $y=$ 2.93 and a cut depth of $w=0.5 \mathrm{~cm}$ offered higher heat transfer rate and friction factor than other twist ratios.
\end{abstract}

\section{Introduction}

The performance of heat exchangers especially for singlephase flows can be enhanced by many augmentation techniques. In general, heat transfer augmentation techniques can be divided into two categories: (1) active techniques which require external power source and (2) passive techniques which do not require external power source. Several experimental studies on heat transfer augmentation techniques using twisted tape as passive technique have been reported in the literature [1-15]. Thereafter and due to the advances in computer hardware and software and consequently increase in computation speed, the CFD modeling technique has been recognized as a powerful and effective tool to gain better understanding of the complex hydrodynamics in many industrial processes. Kumar et al. [16] studied the hydrodynamics and heat transfer characteristics of tube in a pilot scale helical heat exchanger fitted with semicircular plate in the annular area using a commercial CFD package to predict the flow and thermal properties in the heat exchanger tube.
They found that the Nusselt number and friction factor in the inner and outer tubes from the CFD results coincided with the experimental data. Sivashanmugam et al. [17] reported the modeling of heat transfer augmentation in a circular tube fitted with a helical twist insert in a laminar and turbulent flow using CFD. Jayakumar et al. [18] offered a comparison study of CFD simulations and experiment on convective heat transfer in a double pipe helical heat exchanger and developed an empirical correlation for estimation of the inner heat transfer coefficient of a helical coil. Kharat et al. [19] developed heat transfer coefficient correlation for the flue gas side of concentric helical heat exchanger based on both the CFD simulation and experimental work. The correlation was used to analyze the data obtained from CFD and experimental results and to account for the effects of the gap between the concentric coil, tube diameter, and coil diameter on heat transfer coefficient. The predicted results of the correlations were in good agreement with the experimental results within an error band of 3-4\%. Nagarajan and Sivashanmugam [20] reported the simulation of heat transfer augmentation and 
friction factor characteristics of a circular tube fitted with a right-left helical twist insert with a $100 \mathrm{~mm}$ spacer using CFD. The results of the simulated Nusselt number and friction factor for a given flow rate and twist ratio were compared with the experimental data and found a good agreement between the two. Shabanian et al. [21] conducted an experiment and (CFD) modeling on heat transfer, friction factor, and thermal performance of an air cooled heat exchanger equipped with three types of tube insert including butterfly, classic, and jagged twisted tape. They found that the predicted results in terms of turbulence intensity are in good agreement with measured values of Nusselt number and friction factor. Wang et al. [22] explicated the optimum configuration of regularly spaced short-length twisted tape in a circular tube by using computational fluid dynamics (CFD) modeling. Air was used as the test fluid with a turbulent flow with the configuration parameters including the free space ratio $(s)$, twist ratio $(y)$, and rotated angle $(a)$. The predicted results were in good agreement with the experimental data. The results showed that the larger rotation angle yields a higher heat transfer value and greater flow resistance, whereas the smaller twist ratio resulted in better heat transfer performance except for a larger rotation angle at high Reynolds number. Pathipakka and Sivashanmugam [23] performed a CFD simulation on the heat transfer characteristics of $\mathrm{Al}_{2} \mathrm{O}_{3}$ nanofluid in a circular tube fitted with helical twist inserts under constant heat flux using FLUENT version 6.3.26 in a laminar flow. The $\mathrm{Al}_{2} \mathrm{O}_{3}$ nanoparticles in water at different concentrations $(0.5 \%, 1.0 \%$, and $1.5 \%)$ and helical twist inserts with different twist ratios ( $y=2.93,3.91$, and 4.89$)$ were used in the simulation. The data obtained from the CFD simulation were compared with the reported values in the literature for water in a plain tube helical tape inserts. Salman et al. [24] report the application of a mathematical model of the heat transfer enhancement and friction factor characteristics of water in constant heatfluxed tube fitted with elliptical cut twisted tape inserts using FLUENT version 6.3.26. Two types of swirl flow generator, classical and elliptical cut twisted tape with twist ratios $(y=$ $2.93,3.91$, and 4.89) and different cut depths $(w=0.5,1$, and $1.5 \mathrm{~cm}$ ), were used in the CFD simulation. The results show that the enhancement of heat transfer rate and the friction factor induced by elliptical cut twisted tape inserts increases with Reynolds number and decreases with twist ratio. In addition, the results show that the elliptical cut twisted tape with twist ratio $(y=2.93)$ and cut depth $(w=0.5 \mathrm{~cm})$ offered higher heat transfer rate with significant increases in friction factor.

Salman et al. [25] numerically investigated the heat transfer of water in a uniformly heated circular tube fitted with V-cut twisted tape inserts in laminar flow using Fluent version 6.3.26. Classical and elliptical cut twisted tape with twist ratios ( $y=2.93,3.91$, and 4.89$)$ and different cut depths $(w=0.5,1$, and $1.5 \mathrm{~cm})$ was employed for the simulation. The results show that the $\mathrm{V}$-cut twisted tape with twist ratio $(y=$ $2.93)$ and cut depth $(w=0.5 \mathrm{~cm})$ generated the maximum heat transfer rate with significant increases in friction factor. In the present paper, the effects of quadrant-cut twist tape inserts with three twist ratios $(y=2.93,3.91$, and 4.89$)$ and different cut depths $(w=0.5,1.0$, and $1.5 \mathrm{~cm})$ on heat transfer
TABLE 1: Details and thermo-physical properties of materials.

\begin{tabular}{|c|c|}
\hline Parameter & Description \\
\hline \multicolumn{2}{|l|}{ Test section } \\
\hline Inner tube diameter $d_{i}(\mathrm{~mm})$ & 25.4 \\
\hline Outer tube diameter $d_{o}(\mathrm{~mm})$ & 33 \\
\hline Test tube length/mm & 1800 \\
\hline Material of test tube & Steel \\
\hline Density $\left(\mathrm{Kg} / \mathrm{m}^{3}\right)$ & 2719 \\
\hline Specific heat (J/kg K) & 502.48 \\
\hline Thermal conductivity (W/m K) & 16.27 \\
\hline \multicolumn{2}{|l|}{ Twist tape } \\
\hline Tape pitch length $\left(H, 360^{\circ}\right) / \mathrm{mm}$ & 75,100 , and 125 \\
\hline Twist ratio $(y=H / W)$ & $2.93,3.91,4.89$ \\
\hline$H$ & $\begin{array}{l}\text { Linear distance of the } \\
\text { tape for } 360^{\circ} \text { rotation }\end{array}$ \\
\hline$W$ & Width of twisted tape \\
\hline Tape thickness/mm & 0.8 \\
\hline Tape width/mm & 24.5 \\
\hline$(w)$ cut depth/mm & 5,10 , and 15 \\
\hline Material of twist tape & Aluminum \\
\hline \multicolumn{2}{|l|}{ Test conditions } \\
\hline Fluid & Water \\
\hline Reynolds number, Re & $100-2100$ \\
\hline Type of flow in inner tube & Laminar \\
\hline Inlet temperature $/{ }^{\circ} \mathrm{C}$ & 25 \\
\hline
\end{tabular}

Figure 1: Quadrant-cut twisted insert.

and friction factor characteristics in a constant heat-fluxed tube are numerically investigated. The numerical simulations were carried out by solving the mathematical model of swirling flow using a commercial CFD package (FLUENT 6.3.26). Results of interests such as Nusselt number, friction factor, and the twist tape configuration are reported.

\section{Technical Details}

The configuration of the quadrant-cut twisted tape (QCT) inserts is illustrated in Figure 1. An aluminium tape of $0.08 \mathrm{~cm}$ thickness and $2.45 \mathrm{~cm}$ width is uniformly winding over a length of $7.5,10$, and $12.5 \mathrm{~cm}$ to produce twist ratios of $2.93,3.91$, and 4.89 , respectively. The twist ratio " $y$ " is defined as the ratio of the length of one full twist $\left(360^{\circ}\right)$ to the tape width. Three cut depths $(w=0.5,1$, and $1.5 \mathrm{~cm})$ were used for each twisted tape to produce a Parabolic-cut twisted tape. Steel tube with a diameter $(D)$ of $2.54 \mathrm{~cm}$ and length $(L)$ of $180 \mathrm{~cm}$ was used as test section and water was selected as the working fluid. The dimensions and the thermophysical properties of fluid and materials are summarized in Table 1. 


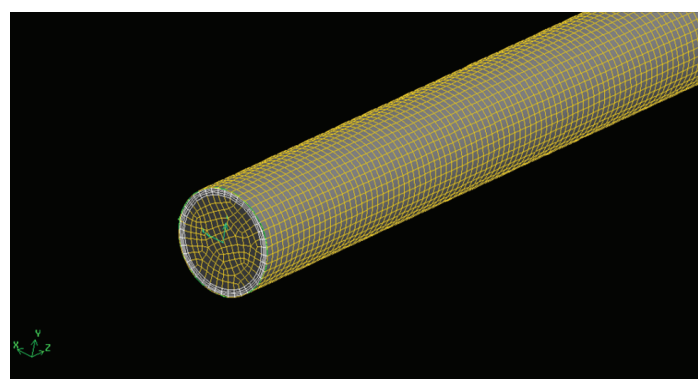

FIGURE 2: Simulation grid for the plain tube.

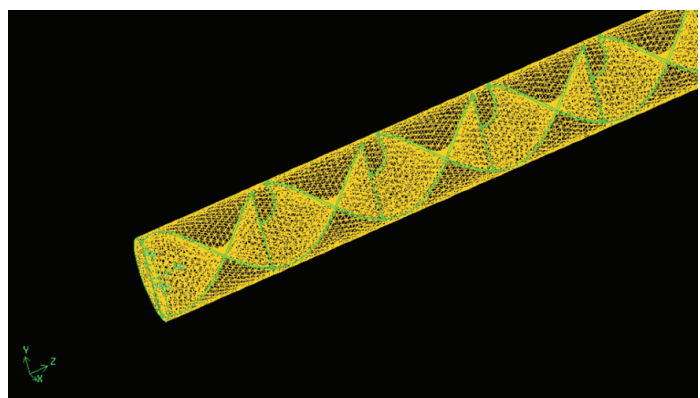

FIGURE 3: Simulation grid for the plain tube with Quadrant-cut twisted tape (QCT) insert.

\section{Geometry and Grid Generation}

GAMBIT, a preprocessor program in FLUENT-6.3.26 package, was used for generating the geometry and grids, whereas FLUENT version 6.3.26 was used in the module preprocessing. The geometry and the grid of the plain tube and quadrant-cut twisted tape inserts are shown in Figures 2 and 3. These geometries were created in GAMBIT and imported into FLUENT for the CFD simulation. The geometries of classical and Quadrant-cut twisted tape inserts with different twist ratios ( $y=2.93,3.91$, and 4.89) and different cut depths $(w=0.5,1$, and $1.5 \mathrm{~cm})$ were made by winding a uniform strip of $25.54 \mathrm{~mm}$ width using the twist option in the sweeping of faces. The twist angle is $360^{\circ}$ with lengths of 75,100 , and $125 \mathrm{~mm}$ for various twist ratios that are generated by using a perpendicular type of sweeping for the entire length of $1800 \mathrm{~mm}$. The volume required for simulation is created by subtracting the twisted tape inserts from the plain tube geometry. The edged meshes were applied to each edge by using the particular interval count, whereas the front circular face is meshed by using tetrahedral and pave type meshing. The mesh face was swept over the entire volume using tetrahedral/hybrid elements and a T-grid type. The boundary conditions for the mesh volume are defined as inlet, outlet, wall, and type of fluid. Water was used as the fluid in the CFD simulation. Subsequently, the mesh file was exported to FLUENT for simulation.

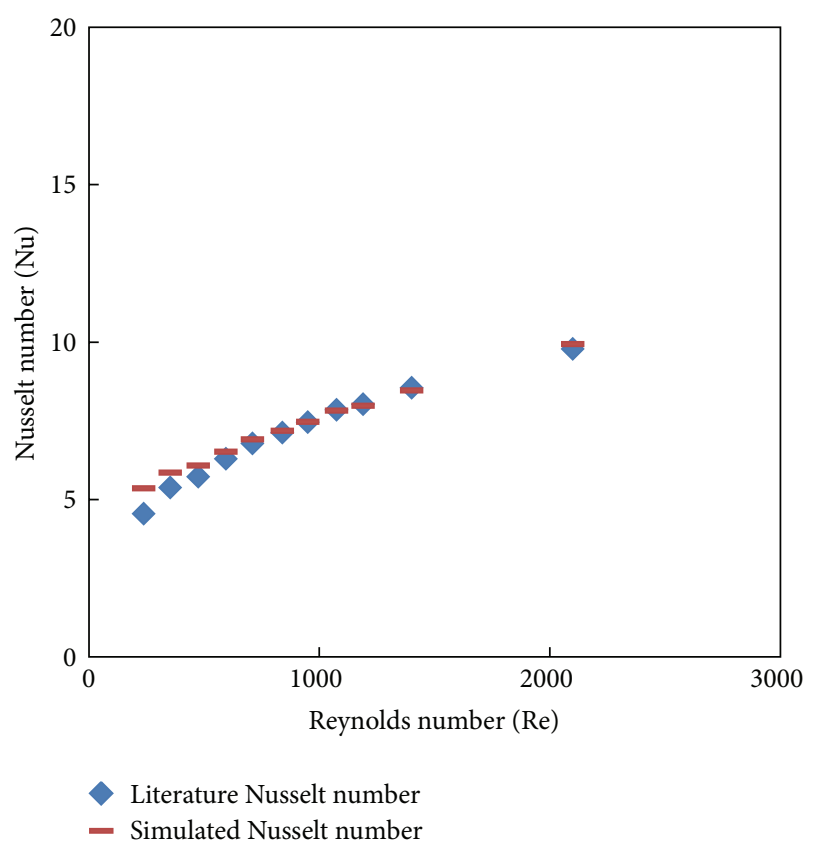

FIgURE 4: Plain tube simulated Nusselt Number versus the literature data.

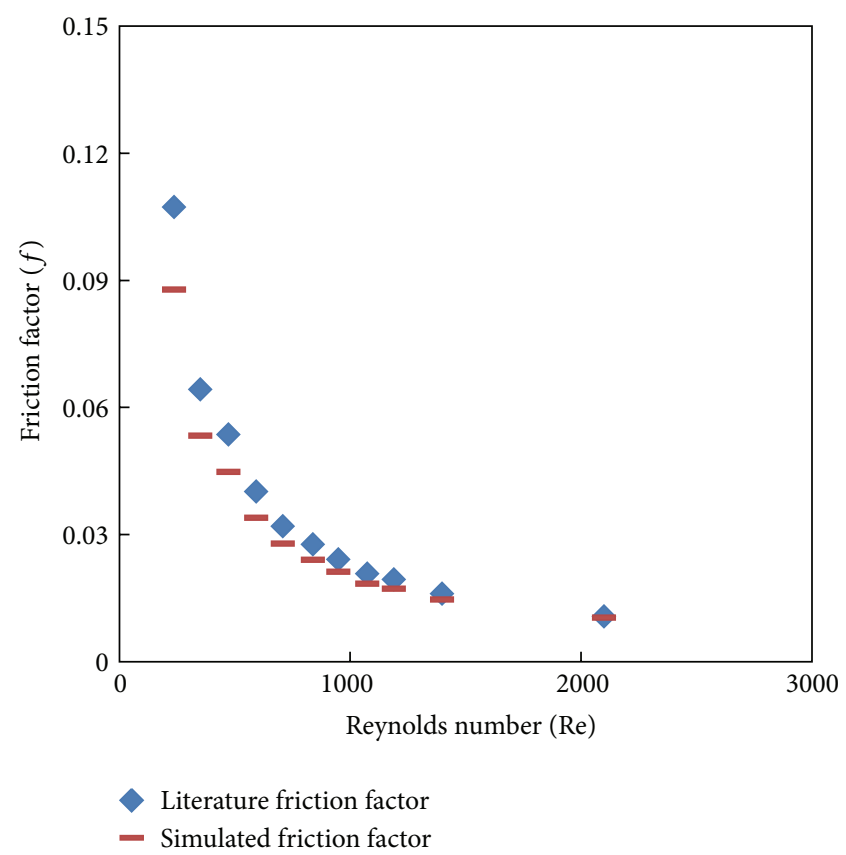

FIGURE 5: Plain tube simulated friction factor versus the literature data.

\section{Numerical Procedure}

The commercial CFD package (FLUENT 6.3.26) was used to perform three-dimensional numerical calculations of the plain tube and twisted tape inserts in a constant heat-fluxed tube using the following governing equations. 


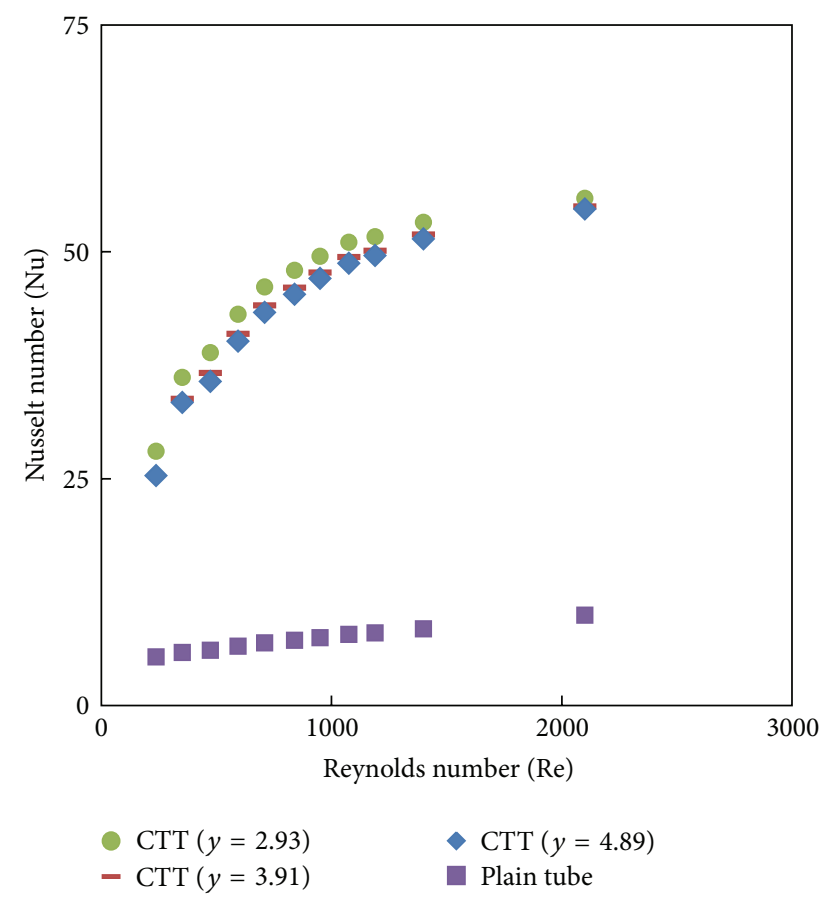

FIGURE 6: Nusselt number of plain tube and CTT with different twist ratios.

(1) Continuity equation for an incompressible fluid:

$$
\frac{\partial p}{\partial t}+\nabla \cdot(\rho \vec{v})=S_{m}
$$

(2) Conservation of momentum:

$$
\frac{\partial v}{\partial t}+\rho(\vec{v} \cdot \nabla) \vec{v}=-\nabla p+\rho \bar{g}+\nabla \cdot \tau_{i j}+\vec{F}
$$

(3) Conservation of energy:

$$
\begin{aligned}
& \rho \frac{\partial}{\partial t}(\rho E)+\nabla \cdot\{\vec{v}(\rho E+\rho)\} \\
& \quad=\nabla \cdot\left\{K_{\mathrm{eff}} \nabla T-\sum h_{i}\left(\vec{\tau}_{\mathrm{eff}} \cdot \vec{v}\right)\right\}+S_{h} .
\end{aligned}
$$

\section{Modeling Parameters}

Numerical values of the mass flow rate and constant heat flux used for simulation are elaborated in Table 2. These data form the basis for the present numerical study. Steel and aluminium have been selected as the material of construction of the plain tube and twisted tapes, respectively. Water was used as the working fluids for all simulation cases.

\section{Numerical Procedure}

The commercial CFD package, Fluent 6.3.26, was used to solve the abovementioned governing equations based on

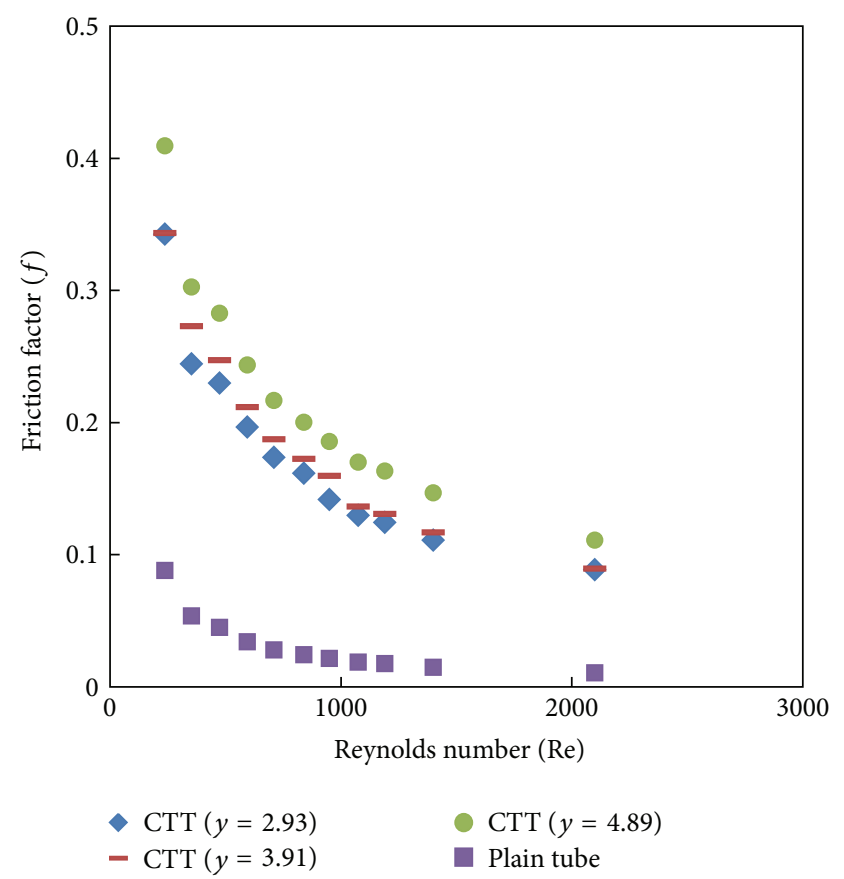

FIgURE 7: Friction factor of plain tube and CTT with different twist ratios.

TABLE 2: Numerical values of the parameters used for simulations [23].

\begin{tabular}{lc}
\hline Mass flow rate $(\mathrm{Kg} / \mathrm{s})$ & Heat flux $\left(\mathrm{W} / \mathrm{m}^{2}\right)$ \\
\hline 0.003 & 240.03 \\
0.005 & 340.77 \\
0.006 & 459.15 \\
0.008 & 563.38 \\
0.010 & 479.85 \\
0.0116 & 1001.57 \\
0.0133 & 1363.26 \\
0.0150 & 1512.68 \\
0.0166 & 1893.56 \\
0.0200 & 2130.05 \\
0.0300 & 2445.25 \\
\hline
\end{tabular}

the defined boundary conditions. The solution sequential algorithm (segregated solver algorithm) has been chosen for this study and solver setting includes implicit formulation, steady (time independent) calculation, viscous laminar model, and energy equation. The SIMPLE algorithm has been selected as the pressure-velocity coupling method and the first-order upwind scheme was used for the energy and momentum equations solution. The following equations are 


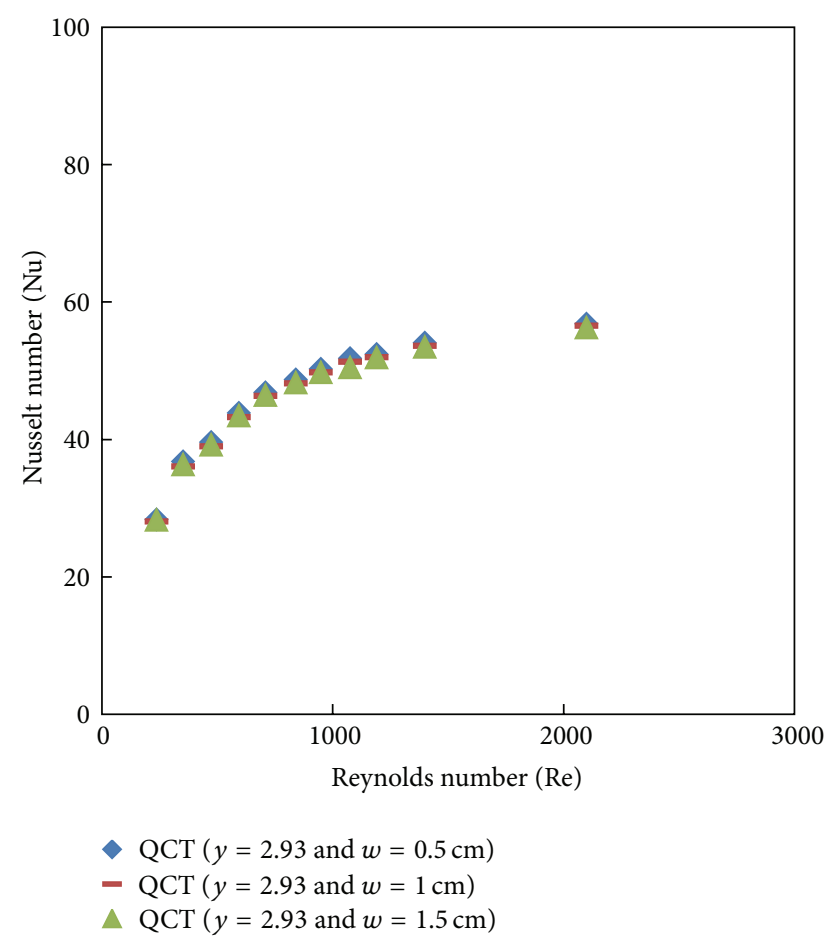

FIGURE 8: Nusselt number for QCT with $y=2.93$ and different cut depths.

used to calculate the Nusselt number $(\mathrm{Nu})$ and the friction factor $(f)$ as a skin friction factor:

$$
\begin{gathered}
\mathrm{Nu}=\frac{h D}{K}, \\
h=\frac{q}{T_{w}-T_{b}}, \\
f=\frac{16}{\operatorname{Re}}, \\
\operatorname{Re}=\frac{\rho u D}{\mu},
\end{gathered}
$$

where $D$ is the tube diameter, $h$ is the heat transfer coefficient, $k$ is the conductivity of water, $q$ is the heat flux on the tube, $T_{w}$ is the tube wall temperature, and $T_{b}$ is the bulk temperature of water $T_{b}=\left(T_{o}+T_{i}\right) / 2, T_{i}$ water inlet temperature, $T_{o}$ water outlet temperature, $\rho$ is the density, $\mu$ is dynamic viscosity, and $u$ is the water velocity.

\section{Grid Dependence}

A test on the grid dependence was conducted to evaluate the effects of grid sizes on the simulated results. In this study, the control volume was divided into a number of nodes (cell) and was tested for $R e=2000$. Five mesh volumes were considered for plain tube and classical and quadrant-cut twist with twist ratio $y=2.93$ and cut depth $0.5 \mathrm{~cm}$ for the grid dependence test. It is observed that all the five mesh volumes have similar results of the Nusselt number with a small percentage of

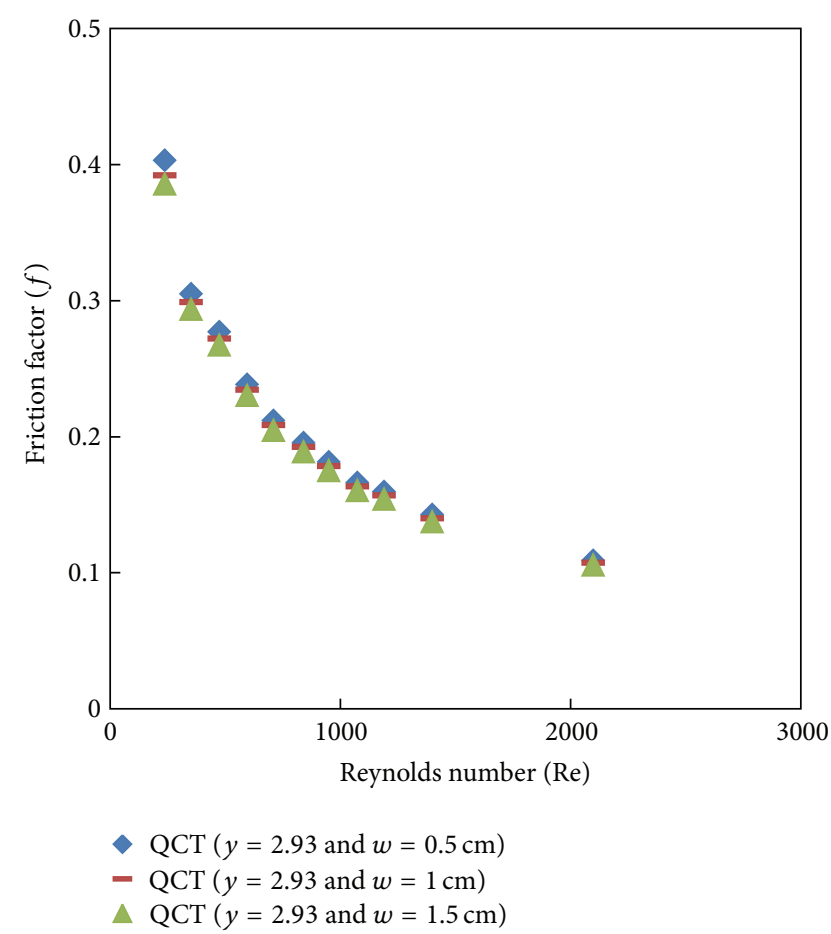

FIGURE 9: Friction factor for QCT with $y=2.93$ and different cut depths.

difference up to $0.5 \%$. Hence, a domain with mesh volumes of 312624,964970 , and 985116 was chosen for the plain tube and classical and quadrant-cut twist tape, respectively, to reduce the computational time.

\section{Results and Discussion}

8.1. Model Validation. The numerical computation was first performed in a particular case of plain tube in order to validate the CFD simulation results with predicted data obtained by Sieder and Tate correlation [26]. The simulated Nusselt number and friction factor for the plain tube are presented in Figures 4 and 5, respectively. These figures show that the results of the present numerical study agree well with the available correlations within $\pm 8 \%$ and $\pm 10 \%$ for Nusselt number and friction factor, respectively.

8.2. Effect of Twist Ratio on Heat Transfer and Friction Factor. Figures 6 and 7 show the variation of the Nusselt number and friction factor with Reynolds number for the classical twisted tape (CTT) inserts with twist ratios $(y=2.93,3.91$, and 4.89), respectively. Figure 6 shows that the Nusselt number increases with increasing Reynolds numbers, and the heat transfer rate with the application of the twist tape is much higher than that of the plain tube. The higher heat transfer rate is most likely due to enhancement of mixing as a result of swirl flow generation. In addition, the twist tape with smaller twist ratio $(y=2.93)$ provides higher heat transfer rate than others twist tapes $(y=3.91$ and 4.89$)$. This means that the smaller twist ratio produced higher turbulent intensity 


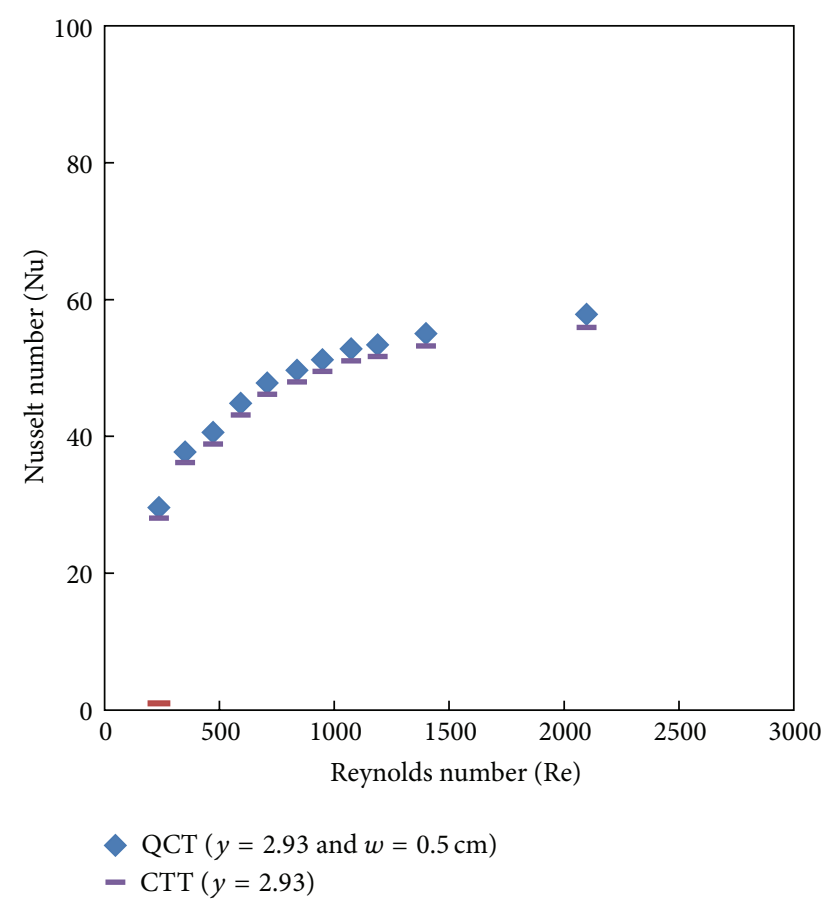

FIGURE 10: Simulated Nusselt number for quadrant-cut twisted tape (QCT) and classical twist tape (CTT).

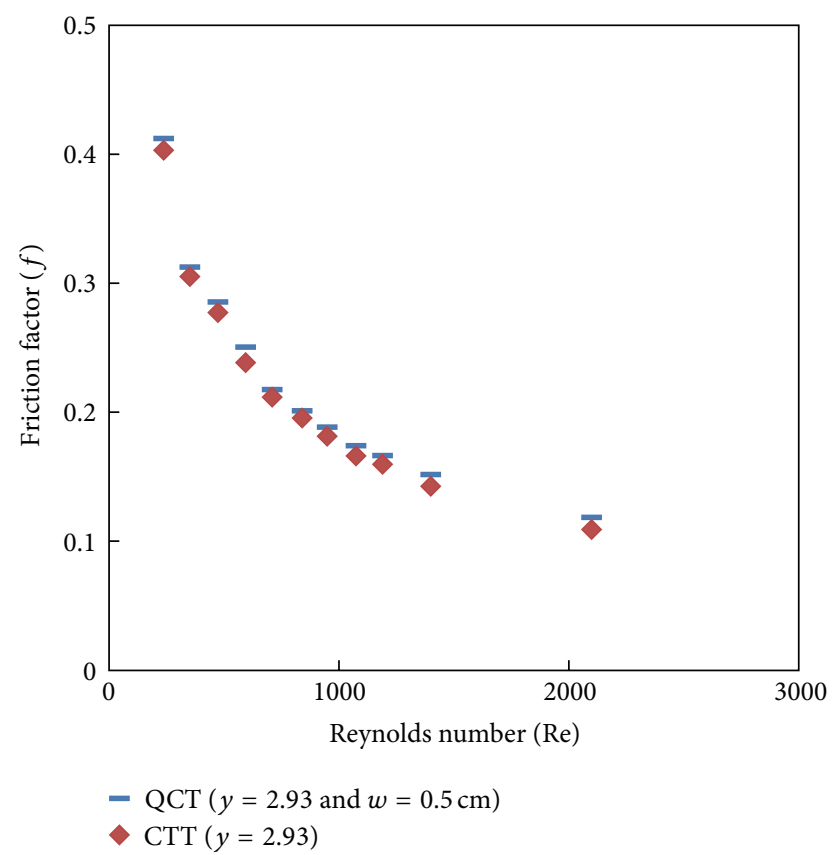

FIGURE 11: Simulated friction factor for quadrant-cut twisted tape (QCT) and classical twist tape (CTT).

with longest flow path than those of larger twist ratios $(y)$. Figure 7 shows the variation of friction factor with Reynolds numbers for different twist ratios. It seems that the friction factor generated by twisted tape insert with smaller twist ratio is significantly higher than the plain tube and other twist ratios. Subsequently, the smallest twist ratio leads to higher

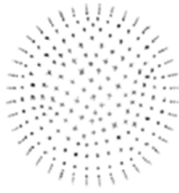

Plain tube

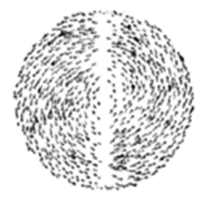

$0.5 \mathrm{~cm}$ QCT

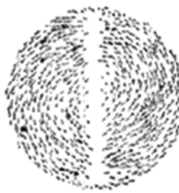

$1 \mathrm{~cm}$ QCT

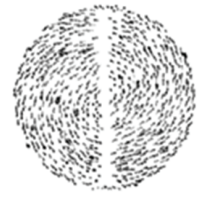

$1.5 \mathrm{~cm}$ QCT
FIGURE 12: The velocity vector of plain tube and tube fitted with (QCT) and different cut depths.

tangential contact between the swirling flow and the tube surface.

8.3. Effect of Cut Depth on Heat Transfer and Friction Factor. Figures 8, 9, 10, and 11 present the variation of the Nusselt number and friction factor with Reynolds numbers for classical and quadrant-cut twisted tape inserts with twist ratio $y=2.93$ and different cut depths $(w=0.5,1$, and $1.5 \mathrm{~cm})$, respectively. These figures show that the Nusselt number and friction factor increased with decreasing cut depth at the same value of the Reynolds number. This phenomenon is due to the combined effects of the swirling flow and turbulence that occurred at smallest alternative cuts along the edge of the twisted tape resulting in higher destruction of the thermal boundary layer which leads to enhanced mixing between the fluid at the core and the heated surface.

8.4. Velocity Field. The velocity vectors predicted for the plain tube and the quadrant-cut twisted tape inserts with twist ratio $(y=2.93)$ and different cut depths $(w=0.5,1$, and $1.5 \mathrm{~cm})$ are presented in Figure 12. This figure shows the longitudinal and radial vortices generated in the quadrant-cut twisted tape inserts. These vortices play a critical role for disturbing the boundary layer and uniform the temperature in the core flow. Consequently, enhanced mixing by extension heat transfer rate between the fluid at the core and the heated surface can be achieved.

8.5. Temperature Field. Figure 13 shows the contour of temperature field for plain tube and the quadrant-cut twisted tape inserts with twisted ratio $(y=2.93)$ and cut depths $(w=0.5,1$, and $1.5 \mathrm{~cm}$ ). The figure shows that the QCT with a cut depth of $w=0.5 \mathrm{~cm}$ produced better temperature distribution on tube wall than plain tube and other cut depths.

\section{Conclusion}

In the present study, the heat transfer and friction factor of a constant heat-fluxed tube fitted with quadrant-cut twisted tape inserts in laminar flow conditions were simulated using Fluent version 6.3.26. The following conclusions can be drawn from the results of the present study.

(i) The data obtained by simulation are well matched with the literature correlations for plain tube with a discrepancy less than $\pm 8 \%$ for Nusselt number and $\pm 10 \%$ for friction factor, respectively. 


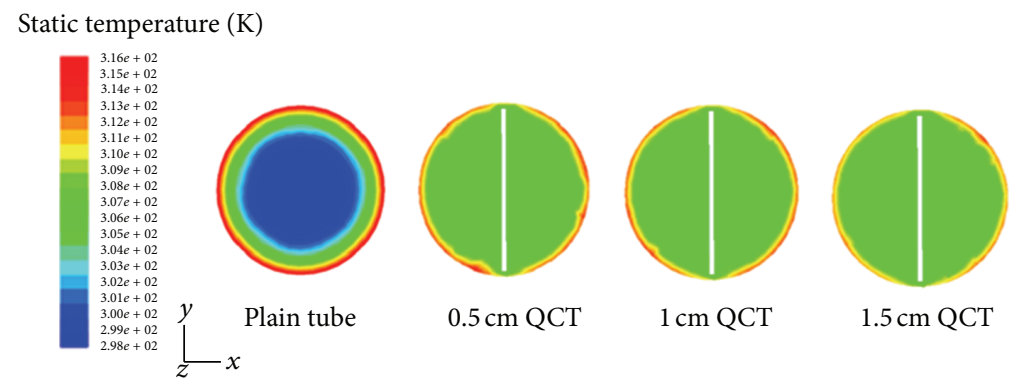

FIgURE 13: The temperature field of plain tube and tube fitted with (QCT) with different cut depths.

(ii) The presence of the tube with quadrant-cut twisted tape inserts yields a higher heat transfer rate $(\mathrm{Nu})$ and friction factor of the plain tube due to the formation of vortices that disturbed the boundary layer, and, thus, enhanced mixing by extension heat transfer rate between the fluid at the core and the heated surface can be achieved.

(iii) Over the range of Reynolds number considered, the tube equipped with the quadrant-cut twisted with $y$ $=2.93$ and cut depth of $0.5 \mathrm{~cm}$ offered the best heat transfer performance as compared to the plain tube and other twisted tapes used.

(iv) The proposed quadrant-cut twisted tape inserts can be used for heat transfer augmentation.

\section{Nomenclature}

$E$ : Energy component in energy equation

$F$ : Force component in momentum equation, $\mathrm{N}$

$F$ : Fanning friction factor

$g$ : Acceleration due to gravity, $\mathrm{m} / \mathrm{s}^{2}$

$k_{\text {eff: }}$ Thermal conductivity in Energy equation, $\mathrm{W} / \mathrm{m} \mathrm{K}$

$m$ : Mass flow rate of fluid, $\mathrm{kg} / \mathrm{s}$

Re: Reynolds number based on internal diameter of the tube, dimensionless

$\mathrm{Nu}$ : Nusselt number, dimensionless

$p$ : Pressure component in momentum equation, $\mathrm{N} / \mathrm{m}^{2}$

$S_{m}:$ Accumulation of mass, $\mathrm{kg}$

$S_{h}$ : Accumulation of energy, J

T: Temperature, ${ }^{\circ} \mathrm{C}$.

$v$ : Velocity component in momentum equation, $\mathrm{m} / \mathrm{s}$

$y$ : $\quad$ Twist ratio (length of one twist $\left(360^{\circ}\right) /$ diameter of the twist), dimensionless.

\section{Greek Symbols}

$\rho$ : Density component in governing equations $\vec{\tau}_{\text {eff }}$ : Stress component in momentum equation, $\mathrm{N} / \mathrm{m}^{2}$.

\section{Acknowledgments}

The authors would like to thank Universiti Kebangsaan Malaysia and Ministry of Higher Education for the financial support and Grant research (FRGS/1/2013/TK07/UKM/01/1).

\section{References}

[1] P. K. Sarma, P. S. Kishore, V. D. Rao, and T. Subrahmanyam, "A combined approach to predict friction coefficients and convective heat transfer characteristics in A tube with twisted tape inserts for a wide range of Re and Pr," International Journal of Thermal Sciences, vol. 44, no. 4, pp. 393-398, 2005.

[2] S. Eiamsa-ard, C. Thianpong, and P. Promvonge, "Experimental investigation of heat transfer and flow friction in a circular tube fitted with regularly spaced twisted tape elements," International Communications in Heat and Mass Transfer, vol. 33, no. 10, pp. 1225-1233, 2006.

[3] S. Eiamsa-ard, "Study on thermal and fluid flow characteristics in turbulent channel flows with multiple twisted tape vortex generators," International Communications in Heat and Mass Transfer, vol. 37, no. 6, pp. 644-651, 2010.

[4] S. Eiamsa-ard and P. Promvonge, "Heat transfer characteristics in a tube fitted with helical screw-tape with/without corerod inserts," International Communications in Heat and Mass Transfer, vol. 34, no. 2, pp. 176-185, 2007.

[5] L. S. Sundar, K. V. Sharma, and S. Ramanathan, "Experimental investigation of heat transfer enhancements with $\mathrm{Al}_{2} \mathrm{O}_{3}$ nanofluid and twisted tape insert in a circular tube," International Journal of Nanotechnology and Applications, vol. 1, pp. 2128, 2007.

[6] P. Sivashanmugam and S. Suresh, "Experimental studies on heat transfer and friction factor characteristics of turbulent flow through a circular tube fitted with regularly spaced helical screw-tape inserts," Applied Thermal Engineering, vol. 27, no. 89, pp. 1311-1319, 2007.

[7] S. Eiamsa-ard, S. Pethkool, C. Thianpong, and P. Promvonge, "Turbulent flow heat transfer and pressure loss in a double pipe heat exchanger with louvered strip inserts," International Communications in Heat and Mass Transfer, vol. 35, no. 2, pp. 120-129, 2008.

[8] A. Kumar and B. N. Prasad, "Enhancement in solar water heater performance using twisted tape inserts," Journal of the Institution of Engineers, vol. 90, pp. 6-9, 2009.

[9] M. Rahimi, S. R. Shabanian, and A. A. Alsairafi, "Experimental and CFD studies on heat transfer and friction factor characteristics of a tube equipped with modified twisted tape inserts," 
Chemical Engineering and Processing, vol. 48, no. 3, pp. 762-770, 2009.

[10] S. Jaisankar, T. K. Radhakrishnan, and K. N. Sheeba, "Experimental studies on heat transfer and friction factor characteristics of thermosyphon solar water heater system fitted with spacer at the trailing edge of twisted tapes," Applied Thermal Engineering, vol. 29, no. 5-6, pp. 1224-1231, 2009.

[11] S. Eiamsa-ard, K. Wongcharee, P. Eiamsa-ard, and C. Thianpong, "Thermohydraulic investigation of turbulent flow through a round tube equipped with twisted tapes consisting of centre wings and alternate-axes," Experimental Thermal and Fluid Science, vol. 34, no. 8, pp. 1151-1161, 2010.

[12] P. Murugesan, K. Mayilsamy, and S. Suresh, “Turbulent heat transfer and pressure drop in tube fitted with square-cut twisted tape," Chinese Journal of Chemical Engineering, vol. 18, no. 4, pp. 609-617, 2010.

[13] J. Guo, A. Fan, X. Zhang, and W. Liu, "A numerical study on heat transfer and friction factor characteristics of laminar flow in a circular tube fitted with center-cleared twisted tape," International Journal of Thermal Sciences, vol. 50, no. 7, pp. 12631270, 2011.

[14] E. Z. Ibrahim, "Augmentation of laminar flow and heat transfer in flat tubes by means of helical screw-tape inserts," Energy Conversion and Management, vol. 52, no. 1, pp. 250-257, 2011.

[15] A. V. N. Kapatkar, A. S. Padalkar, and C. Sanjay Kasbe, "Experimental investigation on heat transfer enhancement in laminar flow in circular tube equipped with different inserts," AMAE International Journal on Manufacturing and Material Science, vol. 1, no. 1, 2011.

[16] V. Kumar, S. Saini, M. Sharma, and K. D. P. Nigam, "Pressure drop and heat transfer study in tube-in-tube helical heat exchanger," Chemical Engineering Science, vol. 61, no. 13, pp. 4403-4416, 2006.

[17] P. Sivashanmugam, P. K. Nagarajan, and S. Suresh, "Experimental studies on heat transfer and friction factor characteristics of turbulent flow through a circular tube fitted with right and left helical screw-tape insert," Chemical Engineering Communications, vol. 195, no. 8, pp. 977-987, 2008.

[18] J. S. Jayakumar, S. M. Mahajani, J. C. Mandal, P. K. Vijayan, and R. Bhoi, "Experimental and CFD estimation of heat transfer in helically coiled heat exchangers," Chemical Engineering Research and Design, vol. 86, no. 3, pp. 221-232, 2008.

[19] R. Kharat, N. Bhardwaj, and R. S. Jha, "Development of heat transfer coefficient correlation for concentric helical coil heat exchanger," International Journal of Thermal Sciences, vol. 48, no. 12, pp. 2300-2308, 2009.

[20] P. K. Nagarajan and P. Sivashanmugam, "CFD Simulation of heat transfer augmentation in circular tube filled with rightleft helical inserts with spacer," International Journal of Food Engineering, vol. 6, no. 1, pp. 1-11, 2009.

[21] S. R. Shabanian, M. Rahimi, M. Shahhosseini, and A. A. Alsairafi, "CFD and experimental studies on heat transfer enhancement in an air cooler equipped with different tube inserts," International Communications in Heat and Mass Transfer, vol. 38, no. 3, pp. 383-390, 2011.

[22] Y. Wang, M. Hou, X. Deng et al., "Configuration optimization of regularly spaced short-length twisted tape in a circular tube to enhance turbulent heat transfer using CFD modeling," Applied Thermal Engineering, vol. 31, no. 6-7, pp. 1141-1149, 2011.
[23] G. Pathipakka and P. Sivashanmugam, "Heat transfer behaviour of nanofluids in a uniformly heated circular tube fitted with helical inserts in laminar flow," Superlattices and Microstructures, vol. 47, no. 2, pp. 349-360, 2010.

[24] S. D. Salman, A. A. H. Kadhum, M. S. Takriff, and A. B. Mohamad, "CFD simulation of heat transfer and friction factor augmentation in a circular tube fitted with elliptic-cut twisted tape inserts," Mathematical Problems in Engineering, vol. 2013, Article ID 163839, 7 pages, 2013.

[25] S. D. Salman, A. A. H. Kadhum, M. S. Takriff, and A. B. Mohamad, "Numerical Investigation of Heat transfer and friction factor characteristics in a circular tube fitted with V-cut twisted tape inserts," The Scientific World Journal, vol. 2013, Article ID 492762, 8 pages, 2013.

[26] E. N. Sieder and C. E. Tate, "Heat transfer and pressure drop of liquids in tubes," Industrial and Engineering Chemistry, vol. 28, no. 12 , pp. $1429-1435,1936$. 


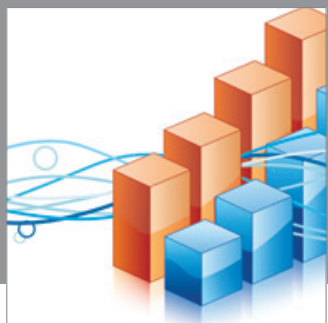

Advances in

Operations Research

mansans

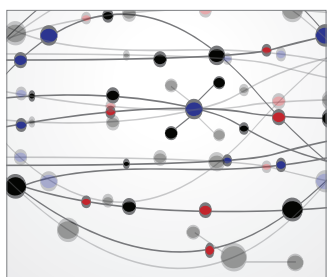

The Scientific World Journal
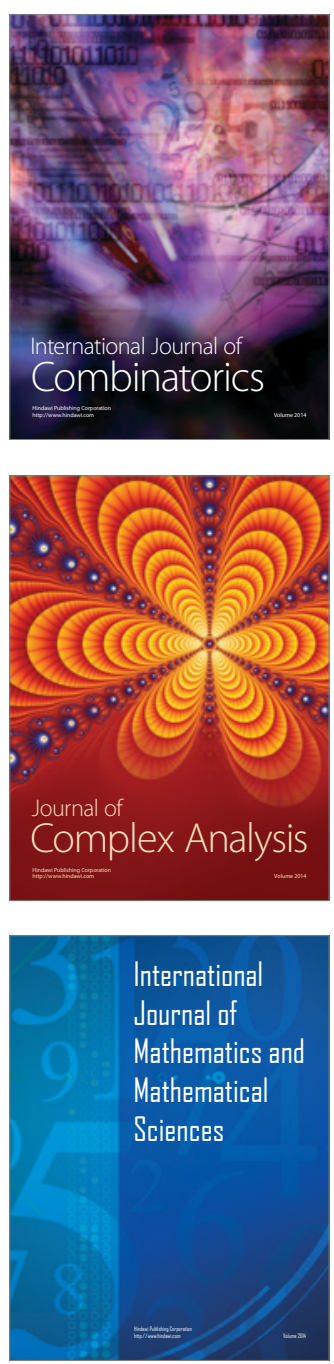
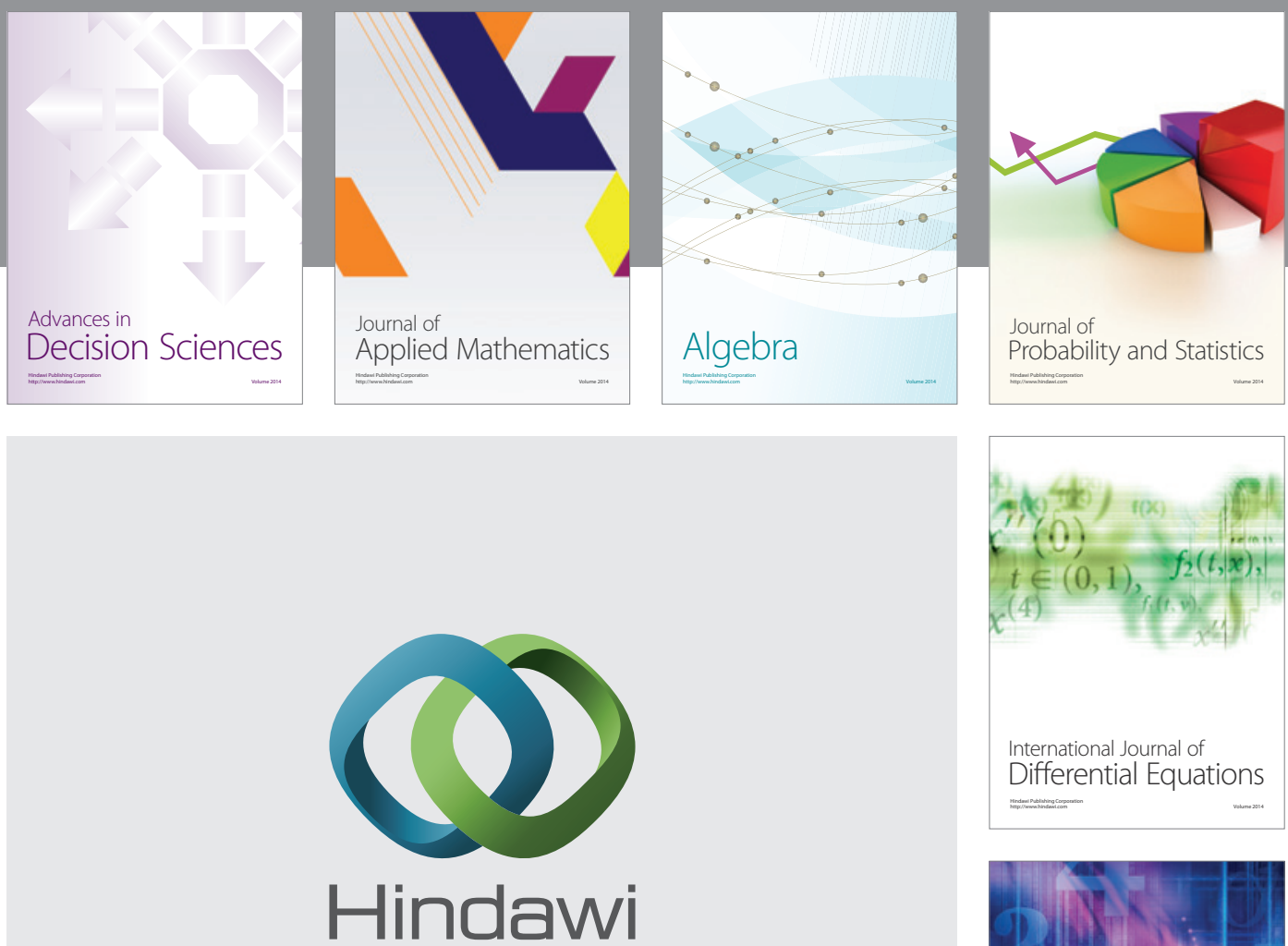

Submit your manuscripts at http://www.hindawi.com
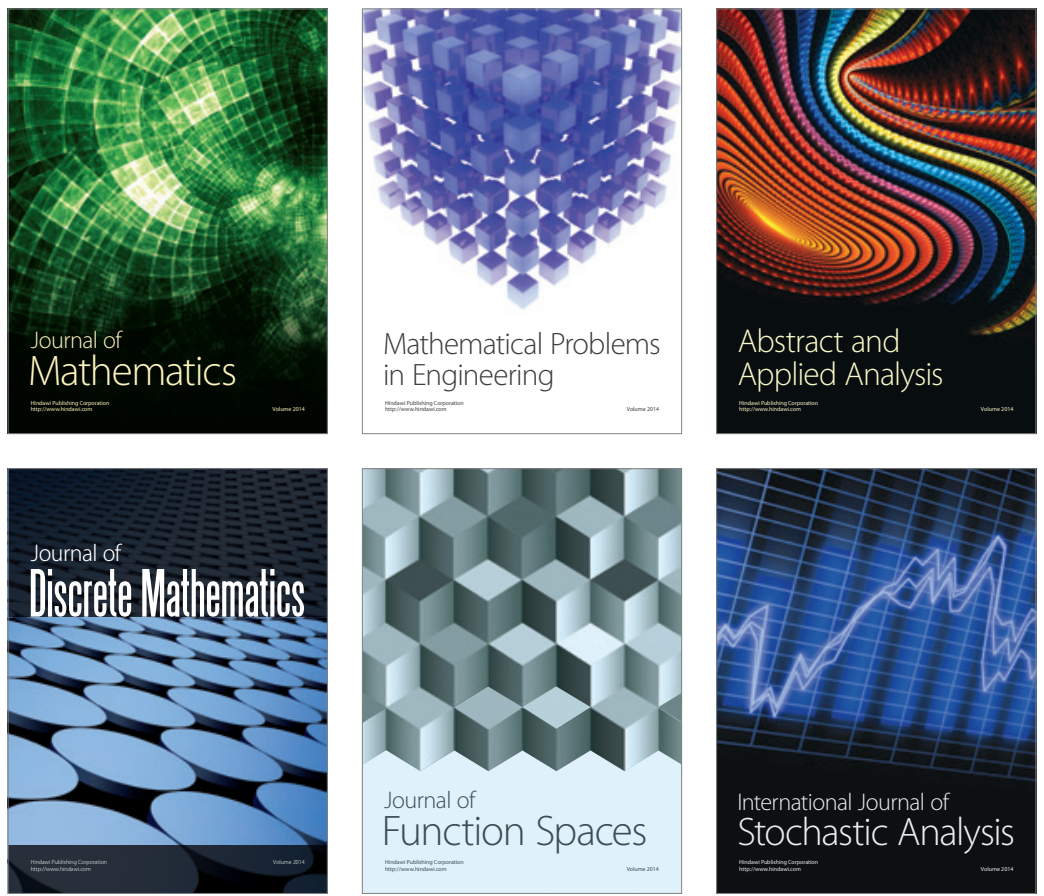

Journal of

Function Spaces

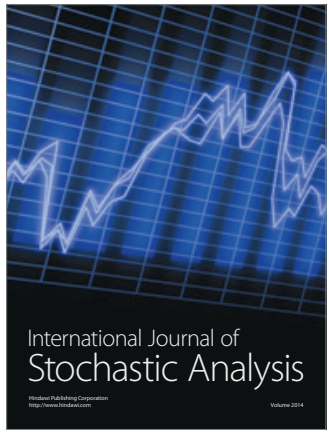

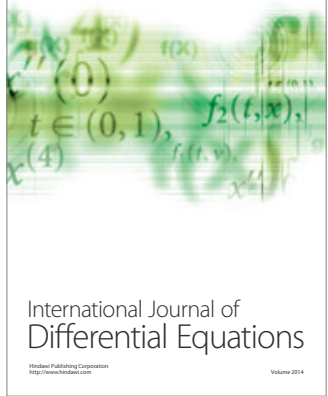
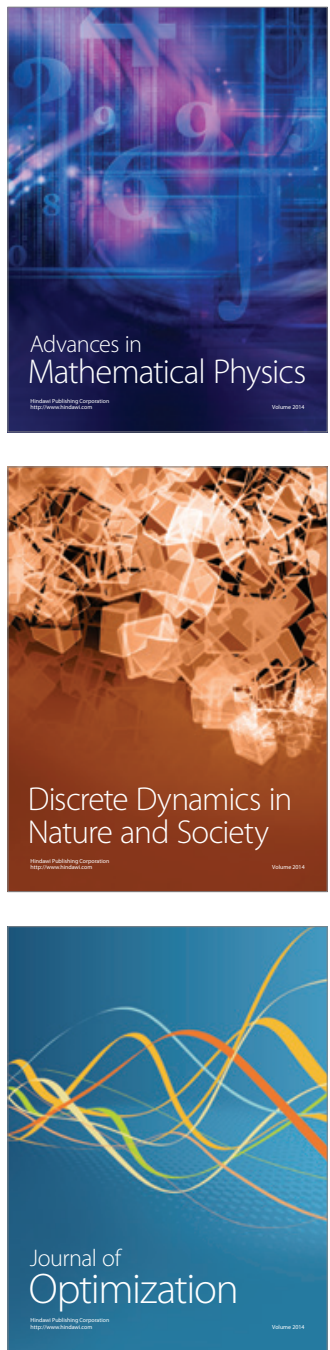